\title{
Energy security in China: the impact of domestic policies and reforms
}

\author{
L. Yao \\ Energy Studies Institute, National University of Singapore, Singapore
}

\begin{abstract}
This study applies both quantitative and qualitative analyses to the energy policies and energy security situation in China between 1980 and 2010. Two primary objectives are achieved in this study. The first objective is to examine how the energy security situation in China has evolved in the past 30 years. This study establishes a quantitative framework that shows that China's energy security situation has not improved during the economic reform. The second objective of the study is to explore qualitatively why the energy security situation has not improved. To answer the "why" question, the study opens up a new perspective by analysing the relationship between energy security and energy policies from the macroeconomic reform perspective. This study discusses major reforms that took place over 30 years. It finds that China's macroeconomic reform has restricted the formation of China's energy policies and determined its energy security situation. In essence, China's energy policies were only a reaction to the macroeconomic measures. They were not originally intended to improve energy security, but were passive reactions to China's macroeconomic reform. This explains why China did not improve its energy security situation despite 30 years of reform.

Keywords: quantitative framework, energy security, China's energy policy, macroeconomic reform in China.
\end{abstract}

\section{Introduction}

There have been extensive studies that evaluate and measure a country's energy security. The conventional concepts of energy security do not have a comprehensive view. Consequently, indicators and conventional measurements are not able to fully measure a country's overall energy security situation. In 
addition, existing energy security evaluation and measurement tend to have double counting and end up an excessively complicated framework.

This study defines energy security in a comprehensive manner and constructs a quantitative framework on the basis of the concept, which incorporates dimensions as many as possible but reduces the complication at most, and comprehensively reflects the energy security situation. Using the framework, this study examines China's energy security trends starting from the initial period of the economic reform and opening up of Deng Xiaoping Administration in 1980 until the late period of $\mathrm{Hu}$ Jintao Administration in 2010 by analyzing key energy policies implemented in China and their effects on China's energy security situation. The study period is split into six five-year periods, which are also the periods of Five-Year Plans for National Economic and Social Development (FYP) in China, with ending year of each FYP as the representative year for analysis. The six FYPs to be discussed are the sixth (1981-1985), seventh (1986-1990), eighth (1991-1995), ninth (1996-2000), tenth (2001-2005), and eleventh (2006-2010) FYP.

The quantitative results show that China's energy security has not improved over 30 years of economic reform. China's energy security was at its best during the sixth FYP period (1981-1985) and it had been deteriorating until 1995. During the ninth and tenth FYP periods (1995-2000 and 2001-2005, respectively), the situation had improved but was not commensurate to the level of the sixth FYP period. The eleventh FYP period (2005-2010) witnessed worsening energy security situation (see figure 2).

Based on the quantitative results, this study discusses the major energy policies issued by the Chinese government during the examined period (1980 2010) and analyses their impact on China's energy security situation. It also explores the reasons behind the promulgation of these policies and explains why energy security in China has not improved over 30 years of economic reform. It argues that the macroeconomic reform in China affects and constrains its energy policies. The energy policies, like a bird, just cannot fly out of the cage of macroeconomic reform. China's energy policies are not originally intended to improve its energy security. That is why the energy security situation in China cannot be improved despite the government's continuous efforts to make it better.

\section{Concepts and frameworks of energy security}

This section reviews the existing energy security concepts and frameworks, and constructs a quantitative framework (4-As framework) to evaluate energy security situation in China.

\subsection{Existing concepts and frameworks of energy security}

The concept of energy security has many facets. Various studies [1-4], attempt to define energy security with different components but the most frequently cited definition is reliable and adequate supply of energy at reasonable prices. These 
three components of energy security cover mainly two dimensions of the concept: the economic and technology dimensions. On the basis of these two dimensions, several studies, [3,5], add a new dimension - the environmental dimension - to the energy security concept when environmental protection has been increasingly drawing public attention. Several organizations [6, 7], incorporate the environmental aspect when defining energy security.

These facets show that energy security is an issue so complex that a holistic approach is needed to address it so as to "capture the complexity of the concept" (Sovacool and Mukherjee [8]). A few attempts of 'holistic notions' have been put forward. For example, an early framework suggested by Chang and Yong [9] incorporates the availability of resource (AV), the applicability of technology (AP), and the acceptability by society (AC) to analyze the perspectives of major oil firms including their perceptions of energy developments and projections of energy potentials. Chester [10] uses a four-dimensional grid of availability, adequacy of capacity, affordability and sustainability to examine Australia's existing and proposed policies that drive the country's energy security in terms of each of the four dimensions. Kruyt et al. [11] classify energy security dimensions by the availability, accessibility, affordability and acceptability of energy and use them to analyze energy security of Western Europe for the next few decades. Von Hippel et al. [5] establish a framework of six dimensions to identify the relative benefits and costs of the future energy paths driven by energy policies.

The above concepts of energy security and the frameworks to evaluate the level of energy security show that the notion of energy security has become multi-dimensional. The following subsection constructs a comprehensive definition, but it does not seek to incorporate as many dimensions that have arisen in the literature as possible but selects an absolutely minimum number of dimensions to reflect the comprehensive concept at the most.

\subsection{Concept and framework to evaluate China's energy security}

The existing concepts and frameworks either do not have comprehensive dimensions, or have duplicate dimensions that lead to double counting and too complicated frameworks. The concept and framework constructed in the following subsections seek to be comprehensive enough while reduce duplication.

\subsubsection{A new concept of energy security}

This study maintains that a comprehensive and holistic approach should be taken to define energy security. First, fossil fuels face the constraint of a declining rate of production. They will be used in the order of availability, the most cheaply available one is used first (Hotelling [12]). This means that sometime before or at the ultimate depletion of a fossil fuel, other fossil fuel or renewable energy resources will replace the existing resource to ensure the adequate supply of energy. Or, another type of fossil fuel will replace those that are less acceptable or more expensive. In other words, energy reserves and resources determine the availability dimension of energy security. These are the fundamental 
requirements to guarantee energy security. The potential shortfall of energy supplies may put a country at risk. How much energy is available to a country remains a priority the government must take into account (Bielecki [2]). This is the first dimension incorporated in the concept of energy security by this studythe availability of resources (AV).

Technology is required for harnessing and utilizing energy. The resources that are not readily extractable require a more advanced technology. Technological advancement in the exploration and production of fossil fuels can expand the recoverable fossil resources base. Technological advancement in the research and development of renewable energy resources can promote the utilization of new energy sources. Technologies for finding and extracting fossil fuels and harnessing renewable resources are also the determining factors for the availability of resources. This is the second dimension of energy security-the applicability of technologies (AP).

Third, energy and the environment are closely connected. While using fossil fuels are considered a threat to the environment, especially through the greenhouse effect, even using so-called environmentally clean energy resources can harm the environment as well. Utilization of hydropower is detrimental to the local ecosystem and nuclear power plants will seriously damage the environment if nuclear and radiation accidents occur. A more ecological view of energy security needs to be considered (Mulligan [13]). Environmental protection has become a prominent issue of international community, which advocates using safer and cleaner energy resources and greener methods of energy production and consumption. Social and environmental concerns are an indispensable component of the contemporary energy regime. This is the third dimension of energy security-the acceptability by society (AC).

Fourth and last, all the above dimensions, including objective conditions (the availability of resources) and subjective efforts (and the applicability of technologies and the acceptability by society), have one common goal - to make energy resources affordable to the population. Affordability comprises three elements: reasonable and stable energy prices, equitable access to energy resources, and high quality of energy resources provided to consumers. This constitutes the fourth dimension of energy security-the affordability of energy resources $(\mathrm{AF})$.

\subsubsection{The 4-As framework to evaluate energy security in China}

Based on the comprehensive notion that encompasses four essential dimensions of AV, AP, AC, and AF, the 4-As framework to measure China's energy security is established. Twenty indicators are selected with five being allocated to each dimension. The twenty indicators are: AV indicators of coal reserve-toproduction ratio, oil import dependence ratio, natural gas reserve-to-consumption ratio, availability factor of conventional thermal electricity, and availability factor of non-thermal electricity; AP indicators of energy intensity, gross generation efficiency of fossil fuel-fired power plants, crude oil distillation capacity, patents owned by LME (State-owned) in coal mining and dressing and petroleum and natural gas extraction industries, and Energy industry technical 
updating and transformation investment/Investment in fixed assets of stateowned units in energy industry; $\mathrm{AC}$ indicators of share of China's $\mathrm{CO}_{2}$ emissions out of global $\mathrm{CO}_{2}$ emissions, China's $\mathrm{SO}_{2}$ emissions, the volume of soot emissions, share of renewable energy out of total electricity generation, and share of nuclear energy out of total electricity generation; AF indicators of growth rate of ex-factory price index for coal, growth rate of ex-factory price index for petroleum, growth rate of ex-factory price index for electricity, volatility of coal prices, and energy consumption per capita. These indicators are based on the existing energy security indicators and taking into account China's conditions and data availability. Relevant data are collected for each indicator. The data are then converted into ordinal values and marked on axes.

With the four points on the axes, a rhombus grid is constructed corresponding to each period of China's energy policy situation. Under the ideal situation, each ' $A$ ' hits the highest value in its dimension when energy security is in perfect condition. However, it is hard to achieve 'perfect' energy security no matter in which period the country is. Different periods have different shapes and areas of different grids, which indicate the relevant energy security status in each period.

The 4-As framework is most useful to depict trends of China's energy security situation dynamically rather than to provide an absolute dichotomy between energy security and energy insecurity. To make the collected data comparable, the data are coded and normalized on a scale of ordinal values. The scoring range of the scale is from 1 to 10 . The higher score means a better energy security situation. Figure 1 shows the 1980 rhombus, the benchmark of the study. Figure 2 illustrates the evolution trends of energy security situation in China. The six rhombuses represents energy security situation of the ending year of six FYPs (Yao and Chang [14]).

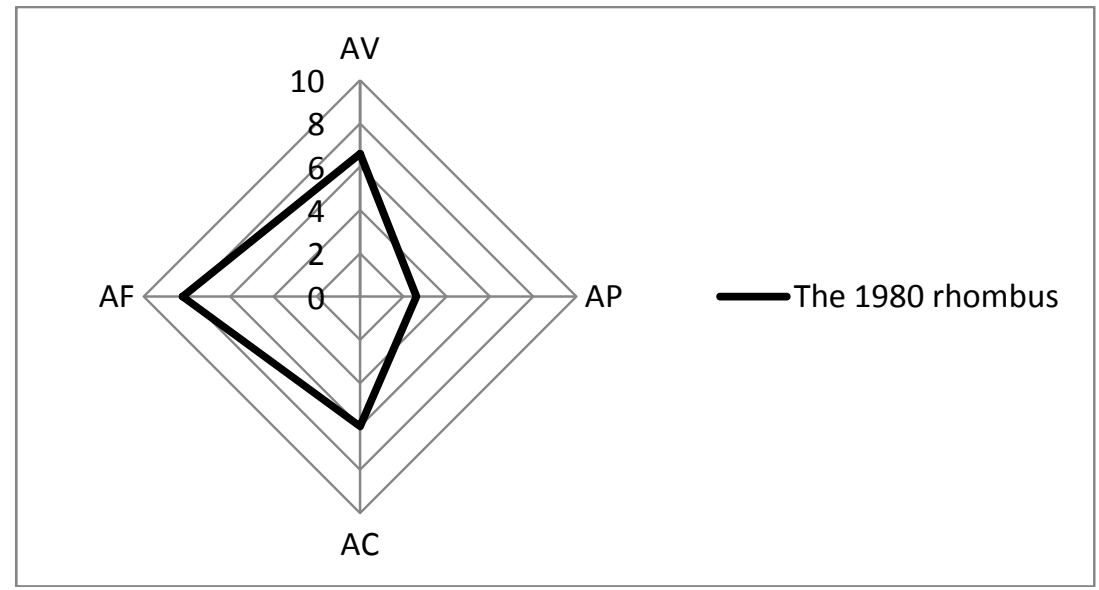

Figure 1: Energy security status of 1980. (The benchmark for this study is 68.04 sq. units.) 
1985 (72.52 sq. units) 1990 (59 sq. units) 1995 (43.92 sq. units)

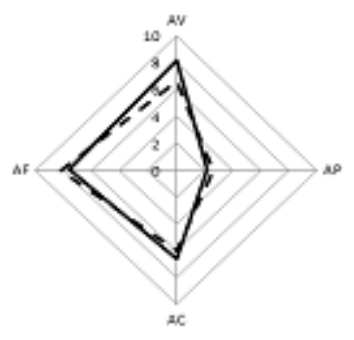

2000 (52.48 sq. units)

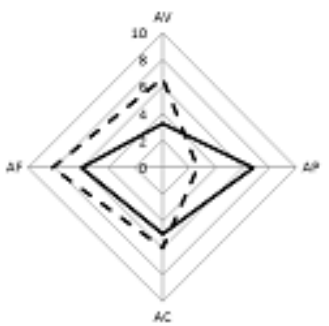

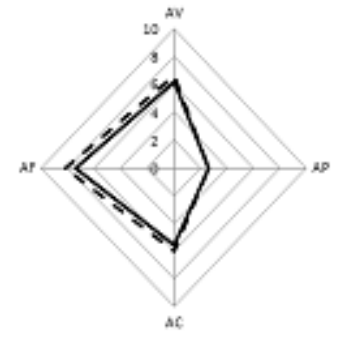

2005 (70.84 sq. units)

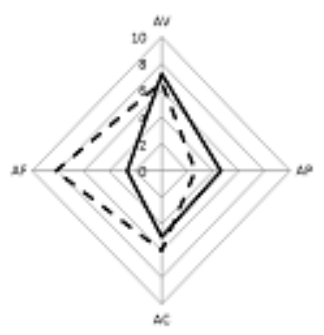

2010 (62.32 sq. units)
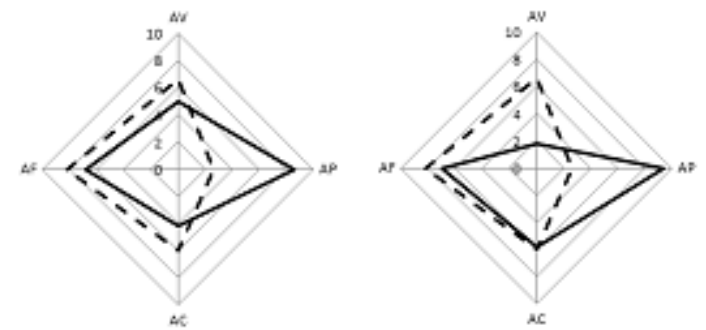

Figure 2: Evolution of energy security situation in China. (The dotted rhombus is the 1980 one.)

\section{Energy policy evolution and macroeconomic reform in China}

Figure 2 illustrates that China's energy security situation did not improve during its three decades of economic reform. This section discusses China's macroeconomic reform, energy policies, and their impacts on its energy security situation from 1980 to 2010, and explains why the situation did not improve. The economic reform could be categorized into three phases covering Deng Xiaoping, Jiang Zemin, and $\mathrm{Hu}$ Jintao administrations respectively.

\subsection{Economic reform and energy policies: the first phase (1980-1992)}

China's economic reform was initiated with the Third Plenary Session of the Eleventh CCP Central Committee in 1978. The Session clearly delivered the thought of decentralization of economic power to the lower levels of the economy, which gave much room for the economic reform at the micro-level. The first micro-level reform is the introduction of Household Responsibility System (HRS) and the development of town and village coal mines (TVCMs).

\subsubsection{Household Responsibility System and town and village coal mines}

Under the HRS, farmers were allotted usage rights of the land with contracted production quotas. The HRS allowed them to make operating decisions 
independently as long as they fulfilled the terms set by the contract with collective organizations. More importantly, the over-quota production could be disposed freely by the households (Hou [15]). This rural household system reform spurred farmers to be more efficient when farming. This led to high agricultural productivity, which meant that fewer workers were needed by the farming work and thus provided surplus labour for the rural non-agricultural sector. Consequently, the HRS provided outlets for expanding town and village enterprises (TVEs). The TVCMs, as one of the major forces of TVEs, began to develop.

The policy shift to the rural non-agricultural sector freed up the pricing system to some extent. The introduction of the two-tier pricing system in the coal sector in 1985 increased incentives of production in the coal industry, particularly the TVCMs. In addition, following the example of HRS, a 'General Contract Programme' was put into practice in the coal sector in 1985, and this further promoted coal production (Andrews-Speed [16]). To sum up, the delegation of autonomy at the local levels and the liberalization in the rural sector deeply affected the indicator of coal reserve-to-production ratio. Besides the expansion of coal production, the government also specified the targets for oil and electricity production and called for energy conservation to compensate for restrictions caused by the low level of energy technology. In short, during the early 1980 s, relatively abundant energy reserves, sound environments unscathed by the fast economic growth, and low and stable energy prices - three factors made the rhombus the largest in 1985, depicting the best energy security situation during the reform period.

\subsubsection{From rural to urban: further and faster reforms}

Success in the rural reform gave the government confidence to extend the reform to the urban area. China's urban reform was mainly focused on improving the performance of State-owned Enterprises (SOEs). Large and medium-sized SOEs were given more autonomy. SOEs in the power sector were encouraged to finance and have their own power generation facilities. The document, 'Provisional Regulation on Encouraging Fund-raising for Power Construction and Allowing Multiple Electricity Prices', reflected the theme of the policy: "who invests, who uses the electricity, and who benefits" (Zhang and Heller [17]). This policy was quite effective in terms of removing the financial constraint in China's power industry. Installed capacity was greatly increased and the indicator of availability factor of conventional thermal electricity was largely affected during that time.

Early economic reform also saw the emergence of a two-tier pricing system. This system consisted of two types of pricing: a government-set price covered by the state plan and a negotiated price for the products above the state quota. In 1985, this system was formally constructed by decontrolling the price of the market portion of industrial goods sold outside the plan. Reflected in the energy sector, the selling prices of crude oil produced above the quota were based on international prices in the early 1980s. In 1986, the central state mines were allowed to sell coal produced over their quotas at a premium (Wright [18]). The 
price growth made the AF indicators of growth rate of ex-factory price index for coal, growth rate of ex-factory price index for petroleum, growth rate of exfactory price index for electricity and volatility of coal prices deteriorate in their ordinal values. In the early 1990s, the central government began to gradually reduce the price differences caused by the two-tier pricing system. From 7 March 1990, a ceiling price was imposed on coal output that exceeded state-quota; from 10 March 1990, ex-factory prices of domestically produced crude oil and some oil products were increased. All these measures made a big step towards the final elimination of the two-tier pricing system (Wright [18]). During 1993-1994, the two-tier pricing system of coal and crude oil were eliminated. The final abolishment of the two-tier pricing system contributed to the lowest ordinal values in the AF dimension in 1995 among the years in calculation.

The relaxation of economy prepared China to speed up reform and marketization. In his report to the Fourteenth National People's Congress of CCP, delivered on 12 October 1992, President Jiang Zemin stated that the government would accelerate the pace of economic reform and establish the socialist market economic system. Since then, China's historical transformation from 'socialist commodity economy' to 'socialist market economy' has begun. A drastic package of reforms to develop 'socialist market economy' was introduced to legitimatize market competition in China. The reforms had profoundly affected the country's energy sector. The following subsection discusses the major reform measures and their impact on the energy industry.

\subsection{Economic reform and energy policies: the second phase (1993-2002)}

The second phase of China's economic reform was a time of rapid economic growth mainly with three categories of reform measures: government structure, national fiscal and financial systems, and SOEs.

\subsubsection{Government structure reform and its impact on energy sector}

The transition to market economy required the creation of new organizational structures within the government. In March 1998, the First Session of the Ninth National People's Congress streamlined the State Council. The central government made attempts to move away from direct interference tactics to macroeconomic regulation methods in governing specialized departments in SOEs. In the energy sector, respective ministries in charge of coal, petrochemical, and power industries have been abolished. Energy conservation was mostly affected by the government restructuring.

In the early reform period, the central government directly invested in energy conservation projects. Energy conservation service centres were established throughout the ministry's systems. As a result of government restructuring, the energy conservation service centres that created channels for increasing the flow of information on energy efficiency technologies, gradually lost their government funding. Some programs were even phased out during the government restructuring. On the other hand, the newly established system expected to promote energy efficiency through market-based instruments had not 
functioned as intended (Sinton et al. [19]). The government's attention to energy conservation had begun to wane.

\subsubsection{Fiscal and financial reforms and their impact on energy sector}

To stem the decline of the revenue/GDP ratio and increase the central government's capability in its macroeconomic management, the State Council issued 'Decisions on Implementing Tax-sharing Fiscal Management System' in December 1993, and implemented it in 1994. The new system standardized tax rates and simplified tax categories. However, these fiscal reform measures had some side effects on energy conservation. In the 1980s, the government had offered tax allowances to encourage enterprises to invest in energy-saving measures. Due to the simplification of the tax system in the 1994 fiscal reform, many of these tax reductions on energy conservation projects and efficient technology development were removed (Andrews-Speed [16]), resulting in the decline of the share of energy conservation investment in the total energy supply.

In order to foster market economy with indirect but effective macroeconomic regulations, the central government decided in 1994 to initiate a new phase of financial reform comprising a new and comprehensive set of financial policies. The most relevant policy to this study was converting old specialized banks into regular commercial banks. This had a direct adverse impact on the energy sector. With the shift of their operational focus from social benefits to economic benefits, banks were reluctant to extend loans for energy conservation projects because they became highly concerned about the borrowers' repayment ability. Consequently, the preferential interest rates offered for energy conservation projects were cancelled. Since 1996, the share of energy conservation investment to the total energy investment has declined in importance (Lin [20]).

\subsubsection{SOEs reform and its impact on energy sector}

In the second half of the 1990s, the government encouraged the establishment of large enterprise groups to enhance their competitiveness in the domestic and foreign markets.

In 1996, Premier Zhu Rongji proposed to corporatize the power industry. In 1997, the State Power Corporation of China (SPCC) was formally established as a state corporation with independent legal status. SPCC put forward mainly three policy measures for the power sector: the corporatization of the subsidiaries at the provincial and regional levels; the expansion of nationwide power grids; and the introduction of market competition into power generation. The power sector reform affected the AV, AP, and AF indicators in the 1990s. The reform led to the closure of small plants, which resulted in the lowest ordinal value of availability factor of conventional thermal electricity in 2000. However, the reform did not create a competitive electricity market, and neither did it create a mature pricing formation mechanism. The indicator of growth rate of ex-factory price index for electricity hit a moderate value in 2000 . The most positive impact of the power sector reform was this: the state enterprises in the power sector contributed largely as the major force of technological advancement in generation efficiency to the increase of ordinal value of gross generation efficiency of fossil fuel-fired power plants until 2000. 
The timing was also right for oil sector reform. In 1998, assets and operations of the Chinese oil industry were reconsolidated into three integrated and territorially protected national oil companies (NOCs) - China National Petroleum Corporation (CNPC), China Petrochemical Corporation (Sinopec), and China National Offshore Oil Corporation (CNOOC)-incorporating almost all state-owned oilfields and refineries (Lin [21]). The oil sector reform made changes in the size and composition of business portfolios, which led to advancement of research and development. This greatly improved the indicator of crude oil distillation capacity in 2000. In face of the pressure from the NOCs and the increasing dependence on foreign oil imports, China adjusted its domestic oil prices. In November 2001, the domestic oil prices were adjusted to peg to package price, namely, the prices of New York, Rotterdam, and Singapore markets. The market mechanism has begun to play a fundamental role in oil pricing. The growing maturity of the oil pricing mechanism made the indicator of growth rate of ex-factory price index for petroleum improve much in 2000 compared to its lowest ordinal value in 1995 .

\subsection{Economic reform and energy policies: the third phase (2003-2010)}

Until 2002, the Chinese government had initially achieved its mission of 'establishing socialist market economy', but it was far from becoming a mature market economy. Premier Wen Jiabao, in his Government Work Report, proposed to work even harder to promote economic reform. He set out to reform the following: rural sector, SOEs, non-public economic sector, financial sector, fiscal and tax systems and investment system, and the market system (including the pricing reform) (Peng and Chen [22]). All these reforms have their respective projections in the energy sector.

SOEs continued to play a central role in the third phase of the reform process. Consequently, energy sector, with a large share of SOEs, has undergone further reforms during this period. China's power sector was disaggregated both vertically and horizontally (Chen [23]). Continued introduction of competition into the power market improved the indicator of availability factor of conventional thermal electricity in 2005. Under the central government's direction of deepening the SOEs reform and establishing big state-owned enterprise groups, resource consolidation became the overarching policy in the Chinese coal industry during the third phase of the reform. The production by large coal industry groups continued to decrease the ordinal value of the indicator of coal reserve-to-production ratio.

Since 2005, the government has decided to proceed with the reform of the energy price formation mechanism. It further reduced government intervention in the resource allocation and price formation, and established a market-oriented resource price formation mechanism. Coal pricing and allocation were fundamentally changed from the government-set or government-indicative system to the market-regulated system. The ordinal value of 'growth rate of exfactory price index for coal' indicator reached a moderate level and remained steady since 2000 . 


\section{Conclusion}

Based on the existing concepts, indicators, and frameworks of energy security, this study constructs a quantitative instrument - the 4-As evaluation framework (availability, applicability, acceptability and affordability) - to assess China's energy policies and energy security status. It looks into China's energy security trends starting from the initial period of the economic reform and the opening up of Deng Xiaoping's administration in 1980 and ending with the late period of $\mathrm{Hu}$ Jintao's administration in 2010. This study finds that China's energy security has not improved during its 30 years' of economic reform. The growing appetite for energy resources has made the quantitative value of the availability dimension decline; environmental (acceptability) dimension had deteriorated along with energy utilization, only improving a little recently. The affordability dimension has improved after it hit its worst status in 1995. Although the country's technology has progressed continuously, the improvement of the applicability dimension cannot reverse the overall energy security status to the level of the early reform period.

After quantitatively evaluating the energy security situation in China, this study explores why China's energy security situation has not improved. It finds that China's energy policies and energy security situation are strictly constrained by its macroeconomic reform measures. Their passive reaction to China's macroeconomic reform means that specific policies or programs are formulated independently under each macroeconomic reform measure. China's economic reform and energy policies do not have a worked-out plan. They cannot be put into a unified framework and strategy, and this determines that China does not and cannot have coherent energy policies. China's economic reform has definitely affected China's energy policies by all means. Energy policies are just passively reactive to the economic reform. This is the logic of reform: Reform is just irreversible. The logic of how the reform affects energy policies and frames energy security situation in China explains why China's energy policies are not and cannot be proactively designed to improve energy security. As China undergo further economic reform, the impact on energy policies and energy security will become more prominent.

\section{References}

[1] Yergin, D., Energy Security in the 1990s. Foreign Affairs, 67 (1), pp. 110132, 1988.

[2] Bielecki, J., Energy security: is the wolf at the door? The Quarterly Review of Economics and Finance, 42 (2), pp. 235-250, 2002.

[3] International Energy Agency, World Energy Outlook 2007: China and India Insights, OECD/IEA: Paris, 2007.

[4] Chang, Y., \& Lee, J. L., Electricity market deregulation and energy security: study of the UK and Singapore electricity markets. Int. J. Global Energy Issues, 29 (1/2), pp. 109-132, 2008. 
[5] von Hippel, D., Suzuki, T., Williams, J. H., Savage, T., \& Hayes, P., Energy security and sustainability in Northeast Asia. Energy Policy, 39 (1), pp. 6719-6730, 2011.

[6] Asia Pacific Energy Research Centre, A Quest for Energy Security in the 21st Century: Resources and Constraints. APERC: Tokyo, 2007.

[7] United Nations Development Programme, World Energy Assessment Overview: 2004 Update, UNDP: New York, 2004.

[8] Sovacool, B. K., \& Mukherjee, I., Conceptualizing and measuring energy security: A synthesized approach. Energy, 36 (8), pp. 5343-5355, 2011.

[9] Chang, Y., \& Yong, J., Differing perspectives of major oil firms on future energy developments: An illustrative framework. Energy Policy, 35, pp. 5466-5480, 2007.

[10] Chester, L. The (default) strategy determining the security of Australia's energy supply. Second International Association for Energy Economics (IAEE) Asian Conference. http://www.business.curtin.edu.au/files/Chester L_2008.pdf

[11] Kruyt, B., van Vuuren, D. P., de Vries, H. M., \& Groenenberg, H., Indicators for energy security. Energy Policy, 37 (6), 2166-2181, 2009.

[12] Hotelling, H., The Economics of Exhaustible Resources. The Journal of Political Economy, 39 (2), pp. 137-175, 1931.

[13] Mulligan, S., Energy, Environment, and Security: Critical Links in a PostPeak World. Global Environmental Politics, 10 (4), pp. 79-100, 2010.

[14] Yao, L., \& Chang, Y., Energy Security in China: A Quantitative Analysis and Policy Implications. Energy Policy, forthcoming.

[15] Hou, J., Economic reform of China: Cause and effects. The Social Science Journal, 48 (3), 419-434, 2011.

[16] Andrews-Speed, P., Energy Policy and Regulation in the People's Republic of China, Kluwer Law International: The Hague, 2004.

[17] Zhang, C., \& Heller, T. C., Reform of the Chinese Electric Power Market: Economics and Institutions. Working Paper \#3. Stanford University, 2004.

[18] Wright, T., Price Reform in the Chinese Coal Industry. Working Paper No. 66. Asia Research Centre, Murdoch University, 1996.

[19] Sinton, J. E., Levine, M. D., \& Wang, Q., Energy efficiency in China: accomplishments and challenges. Energy Policy, 26 (11), pp. 813-829, 1998.

[20] Lin, J., Energy conservation investments: A comparison between China and the US. Energy Policy, 35 (2), pp. 916-924, 2007.

[21] Lin, K.-C., Macroeconomic Disequilibria and Enterprise Reform: Restructuring the Chinese Oil and Petrochemical Industries in the 1990s. China Journal (60), pp. 49-79, 2008.

[22] Peng, S., \& Chen, L., Reforming China: Major Events (1992-2004), Enrich Professional Publishing (S) Private Limited: Singapore, 2011.

[23] Chen, L., Playing the Market Reform Card: The Changing Patterns of Political Struggle in China's Electric Power Sector. The China Journal, (64), pp. 69-95, 2010. 